\title{
Iron dysregulates APP processing accompanying with SAPP $\alpha$ cellular retention and $\beta$-secretase inhibition in rat cortical neurons
}

\author{
Yu-ting $\mathrm{CHEN}^{1,3}$, Wu-yan $\mathrm{CHEN}^{1}$, Xiao-tian $\mathrm{HUANG}^{1}$, Ye-chun $\mathrm{XU}^{1, *}$, Hai-yan ZHANG ${ }^{1,2, *}$ \\ ${ }^{1}$ CAS Key Laboratory of Receptor Research, Shanghai Institute of Materia Medica, Chinese Academy of Sciences, Shanghai 201203, \\ China; ${ }^{2}$ State Key Laboratory of Drug Research, Shanghai Institute of Materia Medica, Chinese Academy of Sciences, Shanghai \\ 201203, China; ${ }^{3}$ University of Chinese Academy of Sciences, Beijing 100049, China
}

\begin{abstract}
Amyloid precursor protein (APP) and iron both play pivotal roles in the central nervous system, but whether and how iron influences the processing of endogenous APP in neurons remain unclear. Here, we investigated the regulatory effects and underlying mechanisms of iron on non-amyloidogenic and amyloidogenic processing of APP in rat primary cortical neurons. Treatment of the neurons with ferric ammonium citrate (FAC, $100 \mu \mathrm{mol} / \mathrm{L}$ ) markedly facilitated the non-amyloidogenic processing of APP, as evidenced by a robust increase in $\alpha$-secretase-derived carboxy-terminal fragment $\alpha$ (CTF $\alpha)$. Furthermore, the distribution of sAPP $\alpha$ was altered after iron treatment, and SAPP $\alpha$ remained in the cellular lysates instead of being secreted into the extracellular milieu. Moreover, the levels of APP amyloidogenic products, including SAPP $\beta$ and $A \beta$ were both decreased. We further revealed that FAC did not alter the expression of $\beta$-secretase, but significantly suppressed its enzymatic activity in iron-treated neurons. In a cell-free $\beta$-secretase activity assay, FAC dose-dependently inhibited the activity of purified $\beta$-secretase with an $\mathrm{IC}_{50}$ value of $21.67 \mu \mathrm{mol} / \mathrm{L}$. Our data provide the first evidence that iron overload alters the neuronal SAPP $\alpha$ distribution and directly inhibits $\beta$-secretase activity. These findings shed light on the regulatory mechanism of bio-metals on APP processing.
\end{abstract}

Keywords: iron; neurons; amyloid precursor protein; sAPP $\alpha$; $\beta$-amyloid; $\beta$-secretase; Alzheimer's disease

Acta Pharmacologica Sinica (2018) 39: 177-183; doi: 10.1038/aps.2017.113; published online 24 Aug 2017

\section{Introduction}

Amyloid precursor protein (APP) is a single-pass transmembrane protein that is highly expressed in the central nervous system $(\mathrm{CNS})^{[1]}$. Under normal conditions, APP is predominantly processed through the non-amyloidogenic pathway by a-secretase, thus generating the neuroprotective ectodomain sAPPa and the carboxy-terminal fragment a $(\mathrm{CTFa})^{[2]}$. Alternatively, a small pool of APP is processed via the amyloidogenic pathway through $\beta$-secretase $(B A C E 1)^{[3]}$, thus producing sAPP $\beta$ and CTF $\beta$. CTF $\beta$ is further cleaved by $\gamma$-secretase, thereby yielding $\beta$-amyloid $(A \beta)$. Although the significantly triggered amyloidogenic pathway of APP has been extensively studied in the context of Alzheimer's disease, as reviewed by Zhang $^{[4]}$, the physiological function of APP in the CNS and the possible regulatory mechanisms remain poorly understood.

\footnotetext{
${ }^{*}$ To whom correspondence should be addressed.

E-mail hzhang@simm.ac.cn (Hai-yan ZHANG); ycxu@simm.ac.cn (Ye-chun XU)

Received 2017-03-15 Accepted 2017-04-19
}

Among the heterogeneous genetic and non-genetic factors potentially involved in the etiology of various neurodegenerative disorders, the abnormal accumulation of iron in the CNS has attracted substantial attention. Iron is gradually deposited in selective brain regions during normal aging ${ }^{[5,6]}$, as well as in the progression of neurodegenerative diseases ${ }^{[7-9]}$. Excess iron has been linked to oxidative stress and neuronal damage, because addition of iron to neurons or animals could induce free radical production, mitochondrial dysfunction, and eventually lead to neuronal death ${ }^{[10-13]}$. Therefore, iron accumulation in brain cells must be tightly regulated to maintain essential cellular functions and avoid cytotoxicity. Accumulating evidence supports a role of APP in maintaining brain iron homeostasis. Holo APP and SAPPa have been reported to facilitate iron efflux by stabilizing the cell surface distribution of the iron exporter ferroportin ${ }^{[14,15]}$. In contrast, ablation of APP in primary neurons results in iron retention ${ }^{[16]}$, whereas knocking out APP in mice causes iron accumulation in the brain $^{[17]}$.

Whereas APP influences iron export, the converse is also 
true, as iron modulates APP metabolism. Cellular iron level regulates the translation of APP by acting on the ironresponsive element existing in the $5^{\prime}$-untranslated region of APP mRNA ${ }^{[18]}$. It has also been reported that iron affects APP processing and $A \beta$ production ${ }^{[19-22]}$. However, most previous studies have focused on the effects of iron on APP amyloidogenic processing using transgenic animals ${ }^{[19,20]}$ or cells ${ }^{[20,21]}$ overexpressing APP, and hence the results may not truly reflect the physiological interaction between iron and APP in neurons. Furthermore, the effects of iron on neuronal APP non-amyloidogenic processing remain to be elucidated.

To address these issues, the current study was designed to evaluate the overall effects, as well as the potential mechanisms, of iron overload on both non-amyloidogenic and amyloidogenic processing of APP, by using primary neurons carrying endogenous APP. It is critical to perform experiments directly on neurons, because they are more susceptible to iron overload than many other cell types in the brain ${ }^{[23]}$. More importantly, primary neurons process APP differently from other non-neuronal or even neuronal cell lines ${ }^{[24]}$.

\section{Materials and methods}

\section{Primary cortical neurons culture and treatment}

Cortical cultures of neurons were prepared from 17-d-old embryos of Sprague-Dawley rats, as previously described ${ }^{[25]}$. Briefly, the cortices were rapidly dissected and minced on ice and then digested at $37^{\circ} \mathrm{C}$ in $0.125 \%$ trypsin in the presence of $0.2 \mu \mathrm{g} / \mathrm{mL}$ DNase I for $15 \mathrm{~min}$. Next, the tissues were dispersed into single cell suspension by gently pipetting in highglucose Dulbecco's modified Eagle's medium (HG-DMEM; Gibco, Grand Island, NY, USA) with 10\% fetal bovine serum (FBS; Gibco, Grand Island, NY, USA) and sequentially filtered through 300- and 400-mesh sieves. The cells were placed onto plates or dishes (Corning, NY, USA) pre-coated with poly-Llysine (Sangon Biotech, Shanghai, China) for different experiments. The culture medium was changed from HG-DMEM plus FBS to neurobasal medium (Gibco, Grand Island, NY, USA) supplemented with $0.5 \mathrm{mmol} / \mathrm{L} \mathrm{L}$-glutamine (SigmaAldrich, St Louis, MO, USA) and 2\% B27 (Gibco, Grand Island, NY, USA) $4 \mathrm{~h}$ later. Half of the medium was refreshed every other two days.

After 9 days in vitro (DIV), the culture medium was replaced with fresh neurobasal medium without B27 supplement. Neurons were pretreated for $2 \mathrm{~h}$ with or without $100 \mu \mathrm{mol} / \mathrm{L}$ iron chelator deferoxamine (DFO; Sigma-Aldrich, St Louis, $\mathrm{MO}, \mathrm{USA}$ ) or $300 \mu \mathrm{mol} / \mathrm{L}$ antioxidant $N$-acetylcysteine (NAC; Sigma-Aldrich, St Louis, MO, USA) before another $24 \mathrm{~h}$ incubation with $100 \mu \mathrm{mol} / \mathrm{L}$ ferric ammonium citrate (FAC; Sigma-Aldrich, St Louis, MO, USA). The control group was maintained in the same volume of culture medium without any treatment. In addition, samples for detection of APP CTFa were collected from neurons pretreated with $2 \mu \mathrm{mol} / \mathrm{L}$ $\gamma$-secretase inhibitor Avagacestat (AVA; Selleck, Houston, TX, USA) for $2 \mathrm{~h}$ before another $24 \mathrm{~h}$ incubation without or with FAC so as to observe the direct effects of iron on APP a-cleavage without disturbance from $\gamma$-secretase.

\section{Western blot analysis}

Cell lysates and conditioned medium were separately harvested on ice for further analysis. Lysates were prepared in RIPA buffer $(50 \mathrm{mmol} / \mathrm{L}$ Tris- $\mathrm{HCl}, 150 \mathrm{mmol} / \mathrm{L} \mathrm{NaCl}, 2$ $\mathrm{mmol} / \mathrm{L}$ EDTA, $0.5 \%$ sodium deoxycholate, $1 \%$ Triton X-100, $0.1 \% \mathrm{SDS}, 1 \mathrm{mmol} / \mathrm{L} \mathrm{NaF}, 1 \mathrm{mmol} / \mathrm{L} \mathrm{Na}_{3} \mathrm{VO}_{4}, 1 \mathrm{mmol} / \mathrm{L}$ PMSF, pH 7.4) plus 1\% protease inhibitor cocktail (SigmaAldrich, St Louis, MO, USA), and protein concentrations were determined with a BCA protein assay kit (Pierce, Rockford, IL, USA). Medium was collected from neurons cultured in $10-\mathrm{cm}$ dishes in the presence of protease inhibitor cocktail and centrifuged at $1000 \times \mathrm{g}$ for $8 \mathrm{~min}$ at $4{ }^{\circ} \mathrm{C}$ to remove cell debris. The supernatants were then concentrated with Microcon columns (Millipore, Billerica, MA, USA) with a nominal molecular weight cutoff of $50 \mathrm{kDa}$. The above samples were mixed with loading buffer and boiled for $10 \mathrm{~min}$. Aliquots of cellular lysates or concentrated medium were subjected to $16.5 \%$ Tristricine gels for APP CTF separation or 8\% Tris-glycine gels for the detection of other proteins and then transferred to nitrocellulose membranes (Amersham GE Healthcare, Piscataway, NJ, USA). Membranes were incubated overnight at $4{ }^{\circ} \mathrm{C}$ with antibodies to APP C-terminus (1:5000; Sigma-Aldrich, St Louis, MO, USA), sAPPa (1:100; IBL, Takasaki-Shi, Japan), sAPP $\beta$ (1:500; BioLegend, San Diego, CA, USA), BACE1 (1:1000; Abcam, Cambridge, UK), $\beta$-Actin (1:50 000; Sigma-Aldrich, St Louis, MO, USA) or a-Tubulin (1:5000; Santa Cruz, CA, USA). Density measurements of the bands were performed with ImageJ software.

\section{Quantification of endogenous $A \beta_{1-40}$ by enzyme-linked immune sorbent assay (ELISA)}

Levels of $A \beta_{1-40}$ in the medium were evaluated by ELISA with a commercial kit (Invitrogen, Carlsbad, CA, USA) that specifically recognized mouse and rat $A \beta_{1-40}$. Conditioned medium was collected from neurons in 12-well plates in the presence of protease inhibitor cocktail. After the removal of cell debris by centrifugation, aliquots of medium $(200 \mu \mathrm{L})$ were incubated in antibody-coated wells overnight at $4{ }^{\circ} \mathrm{C}$. After washing, wells were incubated with primary antibody and then horseradish peroxidase-conjugated secondary antibody. After removal of excess secondary antibody and incubation with the chromogen substrate for $30 \mathrm{~min}$, stop solution was added. The optical density of each sample was monitored with a Beckman DTX880 microplate reader (USA) at $450 \mathrm{~nm}$. A standard curve was generated by using the synthetic $A \beta_{1-40}$ supplied with the kit, which was diluted in neurobasal medium $(0-500 \mathrm{pg} / \mathrm{mL})$. The levels of secreted $A \beta$ were normalized to cellular protein concentrations in the culture.

\section{$\beta$-Secretase activity assay}

A $\beta$-secretase assay kit was purchased from Invitrogen, and experiments were performed according to the manufacturer's protocol. The assay was performed in black 384-well microplates. Control and FAC-treated neurons grown in dishes were washed with PBS twice. The cells were scraped mechanically in $100 \mu \mathrm{L}$ cold $\beta$-secretase extraction buffer, collected in tubes, maintained 
on ice for $10 \mathrm{~min}$, and centrifuged at $10000 \times g$ for $5 \mathrm{~min}$ at $4{ }^{\circ} \mathrm{C}$. The supernatant was transferred to a new tube, and protein concentration was quantified with the Bradford method (BIORAD, CA, USA). After quantification, the supernatant was diluted with reaction buffer. An aliquot of each cellular sample (1.5 $\mu$ g protein) in $10 \mu \mathrm{L}$ buffer was mixed with $10 \mu \mathrm{L}$ reaction buffer alone or with buffer containing $\beta$-secretase inhibitor OM99-2 (10 $\mu \mathrm{mol} / \mathrm{L}$ final concentration; Bachem, Bubendorf, Switzerland). Then, $10 \mu \mathrm{L}$ of the substrate supplied with the kit and diluted in reaction buffer was added. The reaction mixture was incubated for $90 \mathrm{~min}$ at $37^{\circ} \mathrm{C}$ in the dark and terminated by the addition of $10 \mu \mathrm{L}$ stop solution. The fluorescence intensity of the enzymatic product was measured at $\mathrm{Ex} / \mathrm{Em}=535 / 585 \mathrm{~nm}$ on a BioTek SYNERGY4 Reader (USA).

To evaluate whether FAC directly inhibited $\beta$-secretase activity, purified BACE1 was used to co-incubate with a dilution series of FAC $(1-500 \mu \mathrm{mol} / \mathrm{L})$. The procedures were the same as the above-mentioned cell-based $\beta$-secretase activity assay. The recorded fluorescence signal was compared with that of an assay mixture without FAC, and the half maximal inhibitory concentration $\left(\mathrm{IC}_{50}\right)$ of FAC toward purified BACE1 was calculated.

\section{Statistical analysis}

Data are expressed as the mean \pm SEM and obtained from at least 3 independent experiments. Significant differences were evaluated with independent-samples $t$ tests, except when multiple treatment groups were compared within individual experiments by an ANOVA test. $P$ values less than 0.05 were considered significant.

\section{Results}

\section{Iron treatment increased APP CTF $\alpha$}

To evaluate the effect of iron on endogenous APP processing, rat primary cortical neurons at DIV 9 were treated with 100 $\mu \mathrm{mol} / \mathrm{L} \mathrm{FAC}$ for $24 \mathrm{~h}$. Cell lysates were harvested to detect the level of full-length (FL) APP with an antibody specifically recognizing APP C-terminus. Western blot results showed that FAC did not alter the protein level of FL-APP $\left(\mathrm{APP}_{\mathrm{FL}}\right)$ (Figure 1). APP is primarily executed by the a-secretase catabolic pathway, which releases sAPPa and membrane-anchored CTFa. CTFa is further processed by the $\gamma$-secretase complex, thus producing p3 plus APP intracellular domain. To observe the effect of FAC on a-secretase-cleavage products without disturbance from $\gamma$-cleavage, neurons were treated with FAC in the presence of the $\gamma$-secretase inhibitor AVA and collected to measure the levels of CTFa with the same antibody used to detect $\mathrm{APP}_{\mathrm{FL}}$. As shown in Figure 1, we observed that FAC up-regulated the non-amyloidogenic processing of APP, as exhibited by the increased level of CTFa in FAC-treated group compared with control group (Figure 1A). Statistically, FAC treatment induced a $40 \%-50 \%$ increase in the level of CTFa $(P<0.01$ vs control group, Figure $1 \mathrm{~B})$.

\section{Iron treatment increased cellular retention of SAPP $\alpha$}

To better understand the regulatory effect of FAC on APP non-amyloidogenic processing in primary neurons, we further examined the level of sAPPa, the amino-terminal cleavage product of a-secretase, in the culture medium and cell lysates. FAC treatment caused an obvious decrease in SAPPa in the culture medium of FAC-treated neurons (Figure 2A), to approximately $70 \%$ that of the control $(P<0.01$, Figure 2B). Although sAPPa is normally liberated into the culture medium $^{[26]}$, several studies have demonstrated that this fragment is also detected in the cell lysates under specific conditions ${ }^{[27-29]}$. We then detected the level of sAPPa in the cell lysates by Western blot analysis. In agreement with results from previous report ${ }^{[26]}$, sAPPa was scarcely detectable in the cell lysates of non-treated neurons (Figure 2A). In contrast to the decreasing tendency in the extracellular medium, FAC incubation resulted in robust retention of sAPPa in cell lysates (Figure 2A), which had levels approximately five times greater than those in the control $(P<0.05$, Figure $2 \mathrm{~B})$.

\section{Iron treatment decreased the secretion of $\mathrm{SAPP} \beta$ and $A \beta$}

In the amyloidogenic processing pathway, APP is cleaved by $\beta$-secretase, thus generating $\mathrm{APP} \beta$ and $\mathrm{CTF} \beta$, and further cleavage of $C T F \beta$ by $\gamma$-secretase yields $A \beta$. The result in Figure $3 \mathrm{~A}$ revealed that exposure to FAC significantly downregulated the level of $\mathrm{APP} \beta$ in the culture medium of primary neurons to approximately $50 \%$ that of the control $(P<0.01)$. Similarly, the secretion level of endogenous $A \beta_{1-40}$ in FACtreated neurons declined by approximately half, as compared with that in the control $(P<0.01$, Figure $3 B)$. This effect of FAC on $A \beta$ secretion was neutralized by the iron chelator DFO $(P<0.01$ vs FAC-treated group), whereas DFO alone did not influence $A \beta$ secretion (Figure $3 B$ ). Since oxidative stress is the primary mediator of iron-induced cascades ${ }^{[30]}$, we considered whether the decreased secretion of $A \beta$ was a generalized but extensive downstream effect of iron-triggered reactive oxygen species accumulation. However, pre-incubation of the neurons with the free radical scavenger NAC did not block the

A

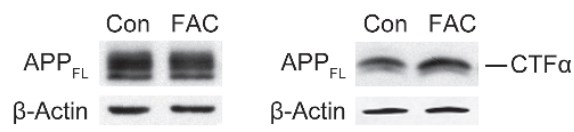

B

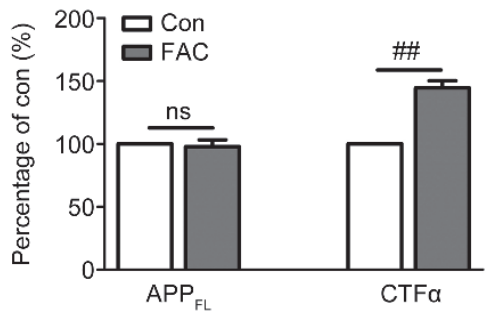

Figure 1. Effects of FAC on the levels of APP full-length (FL) and $\alpha$-carboxyterminal fragments CTF $\alpha$ in primary cortical neurons. Control (Con) and FAC-treated (FAC) neurons were subjected to Western blot analysis. (A) Representative immunoblots of $\mathrm{APP}_{\mathrm{FL}}$ (left) and CTF $\alpha$ (right). Cellular $\beta$-actin was served as loading control. (B) Densitometric analysis of $\mathrm{APP}_{\mathrm{FL}}$ and CTF $\alpha$ immunoblots. ns=non-significant, ${ }^{\# \#} P<0.01$. 
A

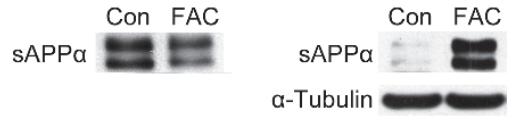

B

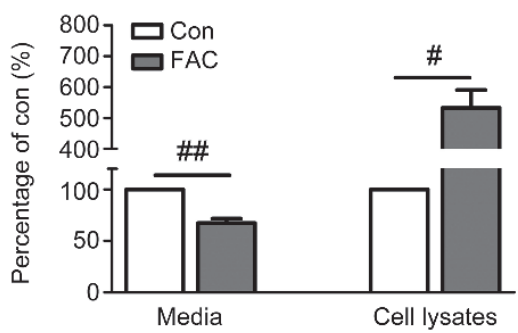

Figure 2. Effects of FAC on the levels of secreted (media) and cell associated (cell lysates) SAPP $\alpha$ in primary cortical neurons. Media or cell lysates were harvested from neurons following $24 \mathrm{~h}$ incubation without or with FAC and separated by SDS-PAGE. (A) Representative immunoblots of SAPP $\alpha$ in the media (left) and cell lysates (right). Cellular $\alpha$-tubulin was served as loading control for cell lysates. (B) Densitometric analysis of sAPP $\alpha$ immunoblots. ${ }^{\#} P<0.05,{ }^{\# \#} P<0.01$.

down-regulation of secreted $\mathrm{A} \beta$ by FAC (Figure 3B).

Iron treatment suppressed the $\beta$-secretase activity of neurons

To elucidate the mechanism underlying the suppressive effect of FAC on APP amyloidogenic processing, we analyzed the influence of FAC on one of the major responsive cleavage enzymes, BACE1, which has been recognized as the $\beta$-secretase of APP in neurons ${ }^{[3]}$. As shown above, FAC decreased the levels of $\mathrm{APP} \beta$ and $A \beta$, both of which are products of APP amyloidogenic processing, thus suggesting that this treatment causes $\beta$-secretase inhibition. To verify this possibility, the protein level and enzymatic activity of $\beta$-secretase were monitored. Immunoblot analysis showed that FAC did not change the expression level of BACE1 in the lysates of primary neurons (Figure 4A). In contrast, FAC treatment notably lowered $\beta$-secretase activity in primary neurons $(P<0.05$ vs control, Figure $4 \mathrm{~B})$. To validate the specificity of the $\beta$-secretase activity assay in cellular samples, the $\beta$-secretase

A

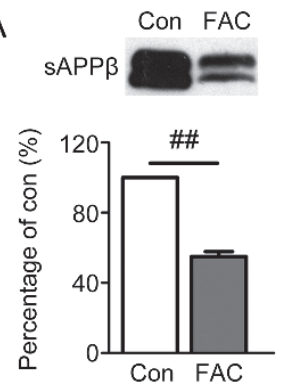

B

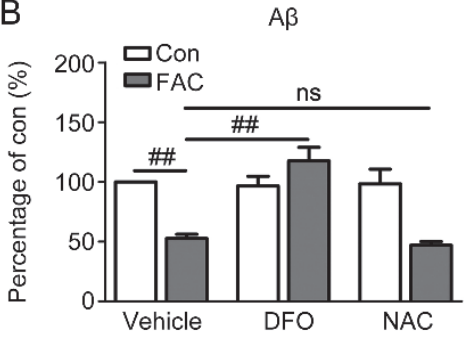

Figure 3. Effects of $F A C$ on the levels of $S A P P \beta$ and $A \beta_{1-40}(A B)$ in the media of primary cortical neurons. (A) A representative immunoblot and densitometric analysis of secreted SAPPB. (B) Conditioned media from neurons pretreated for $2 \mathrm{~h}$ without or with iron chelator DFO or antioxidant NAC and another $24 \mathrm{~h}$ incubation without or with FAC were gathered for ELISA detection of $A \beta$. ns=non-significant, ${ }^{\# \#} P<0.01$. inhibitor OM99-2 was co-incubated with cell lysates. OM99-2 effectively inhibited the activity of $\beta$-secretase to approximately $30 \%$ that of the control in both non-treated and FACtreated neurons $(P<0.01$, Figure 4B).

Iron treatment directly inhibited purified BACE1

Our previous result has indicated that FAC treatment for 24 $\mathrm{h}$ increases intracellular iron levels ${ }^{[11]}$. Together with the evidence of the intracellular distribution of BACE1, it is therefore reasonable to assume direct interaction between iron and BACE1. To further elucidate the possible mechanisms of FAC on $\beta$-secretase inhibition, we then used a cell-free $\beta$-secretase activity assay. As shown by the inhibition curve in Figure 5, FAC inhibited the activity of purified BACE1 in a dosedependent manner, with an $\mathrm{IC}_{50}$ value of $21.67 \mu \mathrm{mol} / \mathrm{L}$ (95\% confidence limit: $14.60-32.17 \mu \mathrm{mol} / \mathrm{L})$. In addition, FAC did not have any direct quenching effect on the fluorescence-based assay of $\beta$-secretase (data not shown).

\section{Discussion}

In the present study, we systematically validated the regulatory effects and underlying mechanisms of FAC on endogenous APP metabolism in primary neurons. The major findings of the present study include the following: 1) iron overload increased the cellular retention of SAPPa in primary cortical neurons; 2) iron overload decreased the extracellular levels of two important APP cleavage products, sAPPa and A $\beta$, shifting away from the normal physiological levels; 3 ) clarified the direct molecular target of iron on BACE1. Given the crucial physiological and pathological roles of APP and its cleavage products in the CNS, it is likely that iron overload may affect neuronal function by perturbing the normal processing of APP.

APP is predominantly processed by a-secretase, thereby releasing sAPPa and CTFa. In our experimental system, we observed an increase in CTFa in primary neurons after FAC treatment (Figure 1), thus suggesting that iron overload facilitates non-amyloidogenic processing of endogenous APP. This finding is also supported by results from a previous study
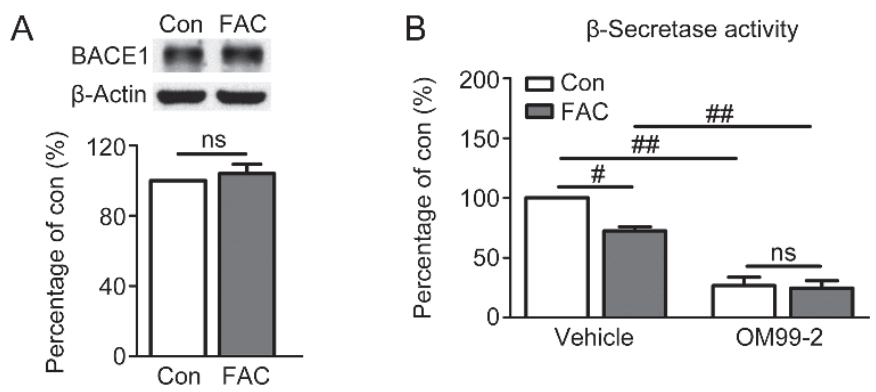

Figure 4. Effects of FAC on $\beta$-secretase protein level and enzymatic activity in primary cortical neurons. (A) A representative immunoblot and densitometric analysis of BACE1. (B) $\beta$-Secretase activity in FAC-treated neurons. The neuronal $\beta$-secretase activity assay was performed by mixing cellular lysates without or with specific $\beta$-secretase inhibitor OM99-2. ns=non-significant, ${ }^{\#} P<0.05,{ }^{\# \#} P<0.01$. 


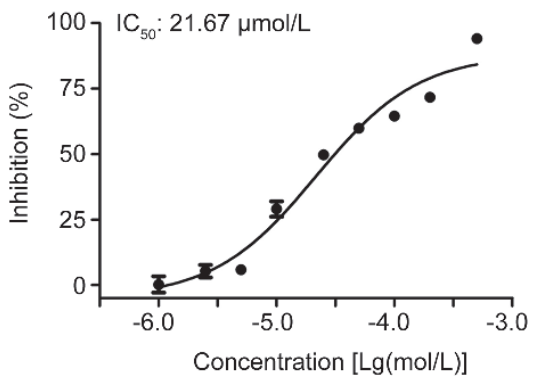

Figure 5. Direct inhibition of FAC on purified BACE1. Dose-dependent inhibitory effect of FAC (1-500 $\mu \mathrm{mol} / \mathrm{L})$ on purified BACE1 and IC 50 value was measured.

performed on PC12 cells ${ }^{[31]}$. Earlier work has indicated that sAPPa is distributed almost exclusively to the extracellular milieu $^{[26]}$. However, subsequent studies have shown that sAPPa can also be detected in cell lysates under certain conditions $^{[27-29]}$. For example, treatment of neurons with aggregated, but not monomeric $A \beta$, results in intracellular retention of $\mathrm{sAPPa}^{[27]}$. As reviewed by Habib ${ }^{[32]}$, sAPPa interacts with multiple cellular proteins and consequently achieves various functions, thus further indicating the potential cellular localization of sAPPa. Interestingly, we observed cellular retention of sAPPa in primary neurons after FAC treatment (Figure 2 ), thus further indicating that altered distribution of SAPPa may be a useful indicator of external stimuli. Although it is unclear what mechanism drives this abnormal retention of sAPPa, there is evidence indicating that the cellular distribution of sAPPa may derive from intracellular cleavage of APP by a-secretase $\mathrm{e}^{[29]}$, or internalization of extracellular sAPPa through cell surface receptors ${ }^{[33]}$.

The physiological functions of sAPPa have been extensively studied. Multiple lines of evidence indicate that sAPPa plays a key role in the outgrowth and survival of neurons, as determined by cell culture studies, as well as exerts neuroprotective effects against iron-mediated oxidative injury, free radical-mediated neurotoxicity, and ischemic spinal cord and traumatic brain injuries (reviewed by Habib ${ }^{[32]}$ ). In contrast, decreased secretion of SAPP or SAPPa is closely associated with neuronal damage under conditions such as abnormal lipid metabolism ${ }^{[34,35]}$, hypoperfusion ${ }^{[36]}$ and cellular aging ${ }^{[37]}$. In the current study, we observed that exposure of primary neurons to FAC decreased the level of secreted sAPPa in the culture media (Figure 2). Together, the evidence of the beneficial role of secreted sAPPa indicates that iron overload mediates a decrease in secreted sAPPa that might lead to harmful consequences. This possibility is of particular relevance to neurological disorders, given that the secretion of sAPPa is affected in multiple CNS diseases including Alzheimer's disease $^{[38]}$, bipolar disorder ${ }^{[39]}$ and amyotrophic lateral sclerosis ${ }^{[40]}$.

Although it is well known that excess $A \beta$ in aggregated form is neurotoxic, physiological concentrations of $A \beta$ have been reported to possess neurotrophic effects and cognitive functions similar to those of $\mathrm{sAPPa}{ }^{[41,42]}$. Blocking $\mathrm{A} \beta$ production in neurons has been shown to cause neuronal death, whereas supplementing with exogenous $A \beta$ peptide at picomolar levels could protect neurons from such damage in a dosedependent manner ${ }^{[43]}$. Moreover, picomolar levels of endogenous $A \beta$ enhance long-term potentials and hippocampaldependent memory in mice ${ }^{[44,45]}$. Furthermore, it has recently been suggested that the loss of function of $A \beta$, rather than its accumulation, has a pathogenic role in $\mathrm{AD}^{[46]}$. In the present study, the concentration of $A \beta_{1-40}$ we detected in the conditioned medium from untreated neurons was $137.0 \pm 7.5 \mathrm{pg} / \mathrm{mL}$ medium (equal to picomolar level), whereas the level of $A \beta_{1-40}$ in the iron-exposed primary neurons was significantly lower and deviated from the physiological level (Figure 3B). It is therefore likely that iron-induced influence on $A \beta$ levels might negatively affect the normal physiological functions of $A \beta$.

Similarly, the decreased secretion of $A \beta$ after iron treatment has also been observed in brain vascular smooth muscle cells ${ }^{[21]}$. Moreover, down-regulatory effects on $A \beta$ levels have recently been shown for other bio-metals such as zinc and copper $^{[47]}$. Nevertheless, in another study, iron overload has been found to promote $A \beta$ secretion in SH-SY5Y neuroblastoma cells $^{[22]}$. The most likely reason for this inconsistency might be the different cell types used for experiments. Our current study was conducted in primary neurons, which are known as highly differentiated cells in which the secretory pathway is under tight control ${ }^{[27]}$, and the processing of APP in primary neurons is different from that in neuronal cell lines ${ }^{[24]}$.

BACE1 is responsible for $\beta$-cleavage of APP amyloidogenic processing. Interestingly, the enzymatic activities of BACE1 in neurons, as well as purified BACE1 were both decreased by FAC (Figure 4B and 5), thus indicating the direct inhibition of BACE1 by FAC. This inhibition at least partially explains the decreased secretion of $\triangle A P P \beta$ and $A \beta$ in primary neurons induced by FAC. Furthermore, the inhibitory effect on BACE1 might be iron specific, because iron in other forms or valance states such as $\mathrm{FeSO}_{4}, \mathrm{FeCl}_{3}$ and ammonium iron sulfate hexahydrate, also exhibited similar inhibitory effects on purified BACE1, whereas other metal ions including zinc, magnesium and copper, had less influence than iron on BACE1 activity (data not shown).

Iron overload induced obvious alternation in both non-amyloidogenic and amyloidogenic processing of neuronal APP. However, the initiation step of the dysregulated processing remains unclear. Previous studies have suggested that inhibition of BACE1 activity increases SAPPa levels ${ }^{[48,49]}$. In contrast, sAPPa has been reported as an extracellular ligand that modulates APP and $A \beta$ metabolism through interactions with various proteins including LRP- 1 and $A \beta$, thereby affecting $A \beta$ clearance. Moreover, sAPPa was confirmed to be an endogenous inhibitor of BACE1 activity, thus potentially decreasing the generation of $A \beta$ (reviewed by Habib ${ }^{[32]}$ ). Therefore, because iron directly inhibits BACE1 activity, it is likely that increased iron firstly induces BACE1 inhibition and the amyloidogenic pathway, in turn promotes the non-amyloidogenic pathway and sAPPa cellular retention. BACE1 activity is further inhibited as a result of increased SAPPa. These abnormal iron-induced changes create a vicious cycle that leads to the 
dysregulation of APP processing in neurons. However, further studies are necessary to provide a comprehensive understanding of the underlying molecular mechanisms.

In summary, we found that iron aberrantly modulates the metabolism of endogenous APP in primary neurons. As dysmetabolism of iron is an important factor involved in multiple CNS disorders, the current data expand understanding of the underlying mechanisms of iron-associated neurological damage.

\section{Acknowledgements}

The authors are grateful to the National Natural Science Foundation of China (№ 81522045 and 31400932).

\section{Author contribution}

Yu-ting CHEN, Ye-chun XU, and Hai-yan ZHANG designed the study; Yu-ting CHEN, Wu-yan CHEN, and Xiao-tian HUANG performed the research; Ye-chun XU and Hai-yan ZHANG contributed new reagents or analytic tools; Yu-ting CHEN, Xiao-tian HUANG, and Hai-yan ZHANG analyzed the data; Yu-ting CHEN and Hai-yan ZHANG wrote the paper.

\section{References}

1 Arai H, Lee VM, Messinger ML, Greenberg BD, Lowery DE, Trojanowski JQ. Expression patterns of beta-amyloid precursor protein (beta-APP) in neural and nonneural human tissues from Alzheimer's disease and control subjects. Ann Neurol 1991; 30: 686-93.

2 Lammich S, Kojro E, Postina R, Gilbert S, Pfeiffer R, Jasionowski M, et al. Constitutive and regulated alpha-secretase cleavage of Alzheimer's amyloid precursor protein by a disintegrin metalloprotease. Proc Natl Acad Sci U S A 1999; 96: 3922-7.

3 Cai H, Wang $\mathrm{Y}$, McCarthy D, Wen $\mathrm{H}$, Borchelt DR, Price DL, et al. BACE1 is the major beta-secretase for generation of Abeta peptides by neurons. Nat Neurosci 2001; 4: 233-4.

4 Zhang $\mathrm{YW}$, Thompson R, Zhang $\mathrm{H}$, Xu H. APP processing in Alzheimer's disease. Mol Brain 2011; 4: 3.

5 Ramos P, Santos A, Pinto NR, Mendes R, Magalhaes T, Almeida A. Iron levels in the human brain: a post-mortem study of anatomical region differences and age-related changes. J Trace Elem Med Biol 2014; 28: 13-7.

6 Acosta-Cabronero J, Betts MJ, Cardenas-Blanco A, Yang S, Nestor PJ. In vivo MRI mapping of brain iron deposition across the adult lifespan. J Neurosci 2016; 36: 364-74.

7 Ward RJ, Zucca FA, Duyn JH, Crichton RR, Zecca L. The role of iron in brain ageing and neurodegenerative disorders. Lancet Neurol 2014; 13: $1045-60$.

8 Raven EP, Lu PH, Tishler TA, Heydari P, Bartzokis G. Increased iron levels and decreased tissue integrity in hippocampus of Alzheimer's disease detected in vivo with magnetic resonance imaging. J Alzheimers Dis 2013; 37: 127-36.

9 Martin-Bastida A, Lao-Kaim NP, Loane C, Politis M, Roussakis AA, Valle-Guzman $\mathrm{N}$, et al. Motor associations of iron accumulation in deep grey matter nuclei in Parkinson's disease: a cross-sectional study of iron-related magnetic resonance imaging susceptibility. Eur J Neurol 2017; 24: 357-65.

10 Uranga RM, Katz S, Salvador GA. Enhanced phosphatidylinositol 3-kinase (PI3K)/Akt signaling has pleiotropic targets in hippocampal neurons exposed to iron-induced oxidative stress. J Biol Chem 2013; 288: $19773-84$.
11 Tao LX, Huang XT, Chen YT, Tang XC, Zhang HY. Acetylcholinesteraseindependent protective effects of huperzine A against iron overloadinduced oxidative damage and aberrant iron metabolism signaling in rat cortical neurons. Acta Pharmacol Sin 2016; 37: 1391-400.

12 Cui ZW, Xie ZX, Wang BF, Zhong ZH, Chen XY, Sun YH, et al. Carvacrol protects neuroblastoma $\mathrm{SH}-\mathrm{SY} 5 \mathrm{Y}$ cells against $\mathrm{Fe}^{2+}$-induced apoptosis by suppressing activation of MAPK/JNK-NF-KB signaling pathway. Acta Pharmacol Sin 2015; 36: 1426-36.

13 Sripetchwandee J, Wongjaikam S, Krintratun W, Chattipakorn $\mathrm{N}$, Chattipakorn SC. A combination of an iron chelator with an antioxidant effectively diminishes the dendritic loss, tauhyperphosphorylation, amyloids-beta accumulation and brain mitochondrial dynamic disruption in rats with chronic iron-overload. Neuroscience 2016; 332: 191-202.

14 Wong BX, Tsatsanis A, Lim LQ, Adlard PA, Bush Al, Duce JA. Betaamyloid precursor protein does not possess ferroxidase activity but does stabilize the cell surface ferrous iron exporter ferroportin. PLoS One 2014; 9: e114174.

15 McCarthy RC, Park YH, Kosman DJ. SAPP modulates iron efflux from brain microvascular endothelial cells by stabilizing the ferrous iron exporter ferroportin. EMBO Rep 2014; 15: 809-15.

16 Duce JA, Tsatsanis A, Cater MA, James SA, Robb E, Wikhe K, et al. Iron-export ferroxidase activity of beta-amyloid precursor protein is inhibited by zinc in Alzheimer's disease. Cell 2010; 142: 857-67.

17 Needham BE, Ciccotosto GD, Cappai R. Combined deletions of amyloid precursor protein and amyloid precursor-like protein 2 reveal different effects on mouse brain metal homeostasis. Metallomics 2014; 6: 598-603.

18 Rogers JT, Randall JD, Cahill CM, Eder PS, Huang X, Gunshin H, et al. An iron-responsive element type II in the 5 -untranslated region of the Alzheimer's amyloid precursor protein transcript. J Biol Chem 2002; 277: 45518-28.

19 Becerril-Ortega J, Bordji K, Freret T, Rush T, Buisson A. Iron overload accelerates neuronal amyloid-beta production and cognitive impairment in transgenic mice model of Alzheimer's disease. Neurobiol Aging 2014; 35: 2288-301.

20 Guo C, Wang T, Zheng W, Shan ZY, Teng WP, Wang ZY. Intranasal deferoxamine reverses iron-induced memory deficits and inhibits amyloidogenic APP processing in a transgenic mouse model of Alzheimer's disease. Neurobiol Aging 2013; 34: 562-75.

21 Frackowiak J, Potempska A, Mazur-Kolecka B. Formation of amyloidbeta oligomers in brain vascular smooth muscle cells transiently exposed to iron-induced oxidative stress. Acta Neuropathol 2009; 117: 557-67.

22 Banerjee P, Sahoo A, Anand S, Ganguly A, Righi G, Bovicelli P, et al. Multiple mechanisms of iron-induced amyloid beta-peptide accumulation in SHSY5Y cells: protective action of negletein. Neuromol Med 2014; 16: 787-98.

23 Gaasch JA, Lockman PR, Geldenhuys WJ, Allen DD, Van der Schyf CJ. Brain iron toxicity: differential responses of astrocytes, neurons, and endothelial cells. Neurochem Res 2007; 32: 1196-208.

24 Nathalie P, Jean-Noel O. Processing of amyloid precursor protein and amyloid peptide neurotoxicity. Curr Alzheimer Res 2008; 5: 92-9.

25 Lei Y, Yang L, Ye CY, Qin MY, Yang HY, Jiang HL, et al. Involvement of intracellular and mitochondrial Abeta in the ameliorative effects of huperzine A against oligomeric Abeta42-induced injury in primary rat neurons. PLoS One 2015; 10: e0128366.

26 Parvathy S, Hussain I, Karran EH, Turner AJ, Hooper NM. Cleavage of Alzheimer's amyloid precursor protein by alpha-secretase occurs at the surface of neuronal cells. Biochemistry 1999; 38: 9728-34.

27 Henriques AG, Vieira SI, Crespo-Lopez ME, Guiomar de Oliveira MA, 
da Cruz e Silva EF, da Cruz e Silva OA. Intracellular SAPP retention in response to Abeta is mapped to cytoskeleton-associated structures. J Neurosci Res 2009; 87: 1449-61.

28 Klein DM, Felsenstein KM, Brenneman DE. Cathepsins B and $L$ differentially regulate amyloid precursor protein processing. J Pharmacol Exp Ther 2009; 328: 813-21.

29 Shin RW, Saido TC, Maeda M, Kitamoto T. Novel alpha-secretase cleavage of Alzheimer's amyloid beta precursor protein in the endoplasmic reticulum of COS7 cells. Neurosci Lett 2005; 376: 149.

30 Galaris D, Pantopoulos K. Oxidative stress and iron homeostasis: mechanistic and health aspects. Crit Rev Clin Lab Sci 2008; 45: 1-23.

$31 \mathrm{Kim} \mathrm{CH}$, Yoo YM. Altered APP carboxyl-terminal processing under ferrous iron treatment in PC12 cells. Korean J Physiol Pharmacol 2013; 17: 189-95.

32 Habib A, Sawmiller D, Tan J. Restoring soluble amyloid precursor protein alpha functions as a potential treatment for Alzheimer's disease. J Neurosci Res 2017; 95: 973-91.

33 Kounnas MZ, Moir RD, Rebeck GW, Bush Al, Argraves WS, Tanzi RE, et al. LDL receptor-related protein, a multifunctional ApoE receptor, binds secreted beta-amyloid precursor protein and mediates its degradation. Cell 1995; 82: 331-40.

34 Racchi M, Baetta R, Salvietti N, lanna P, Franceschini G, Paoletti R, et al. Secretory processing of amyloid precursor protein is inhibited by increase in cellular cholesterol content. Biochem J 1997; 322: 893-8.

35 Tamboli IY, Prager K, Barth E, Heneka M, Sandhoff K, Walter J. Inhibition of glycosphingolipid biosynthesis reduces secretion of the beta-amyloid precursor protein and amyloid beta-peptide. J Biol Chem 2005; 280: 28110-7.

36 Webster NJ, Green KN, Settle VJ, Peers C, Vaughan PF. Altered processing of the amyloid precursor protein and decreased expression of ADAM 10 by chronic hypoxia in SH-SY5Y: no role for the stressactivated JNK and p38 signalling pathways. Brain Res Mol Brain Res 2004; 130: 161-9.

37 Kern A, Roempp B, Prager K, Walter J, Behl C. Down-regulation of endogenous amyloid precursor protein processing due to cellular aging. J Biol Chem 2006; 281: 2405-13.

38 Sennvik K, Fastbom J, Blomberg M, Wahlund LO, Winblad B, Benedikz
E. Levels of alpha- and beta-secretase cleaved amyloid precursor protein in the cerebrospinal fluid of Alzheimer's disease patients. Neurosci Lett 2000; 278: 169-72.

39 Jakobsson J, Zetterberg H, Blennow K, Johan Ekman C, Johansson AG, Landen M. Altered concentrations of amyloid precursor protein metabolites in the cerebrospinal fluid of patients with bipolar disorder. Neuropsychopharmacology 2013; 38: 664-72.

40 Steinacker P, Fang L, Kuhle J, Petzold A, Tumani H, Ludolph AC, et al. Soluble beta-amyloid precursor protein is related to disease progression in amyotrophic lateral sclerosis. PLoS One 2011; 6: e23600.

41 Whitson JS, Selkoe DJ, Cotman CW. Amyloid beta protein enhances the survival of hippocampal neurons in vitro. Science 1989; 243 : 1488-90.

42 Fedele E, Rivera D, Marengo B, Pronzato MA, Ricciarelli R. Amyloid beta: Walking on the dark side of the moon. Mech Ageing Dev 2015; 152: 1-4.

43 Plant LD, Boyle JP, Smith IF, Peers C, Pearson HA. The production of amyloid beta peptide is a critical requirement for the viability of central neurons. J Neurosci 2003; 23: 5531-5.

44 Puzzo D, Privitera L, Fa M, Staniszewski A, Hashimoto G, Aziz F, et al. Endogenous amyloid-beta is necessary for hippocampal synaptic plasticity and memory. Ann Neurol 2011; 69: 819-30.

45 Garcia-Osta A, Alberini CM. Amyloid beta mediates memory formation. Learn Mem 2009; 16: 267-72.

46 Kepp KP. Alzheimer's disease due to loss of function: A new synthesis of the available data. Prog Neurobiol 2016; 143: 36-60.

47 Gerber H, Wu F, Dimitrov M, Garcia Osuna GM, Fraering PC. Zinc and copper differentially modulate amyloid precursor protein processing by gamma-secretase and amyloid-beta peptide production. J Biol Chem 2017; 292: 3751-67.

48 Devi L, Ohno M. Effects of BACE1 haploinsufficiency on APP processing and $A \beta$ concentrations in male and female 5 XFAD Alzheimer mice at different disease stages. Neuroscience 2015; 307 : 128-37.

49 van Maanen EM, van Steeg TJ, Michener MS, Savage MJ, Kennedy $\mathrm{ME}$, Kleijn $\mathrm{HJ}$, et al. Systems pharmacology analysis of the amyloid cascade after $\beta$-secretase inhibition enables the identification of an $A \beta_{42}$ oligomer pool. J Pharmacol Exp Ther 2016; 357: 205-16. 